\title{
In vivo Metabolic Imaging of Insulin with Multiphoton Fluorescence of Human Insulin-Au Nanodots
}

\author{
Chien-Liang Liu, Tzu-Ming Liu, * Tsung-Yuan Hsieh, Han-Wen Liu, Yu-Shing Chen, \\ Cheng-Kun Tsai, Hsieh-Chih Chen, Jong-Wei Lin, Ron-Bin Hsu, Tzung-Dau Wang, \\ Chien-Cheng Chen, Chi-Kuang Sun, and Pi-Tai Chou*
}

\begin{abstract}
$\boldsymbol{F}_{\text {unctional human insulin-Au nanodots (NDs) are synthesized for the in vivo imaging }}$ of insulin metabolism. Benefiting from its efficient red to near infrared fluorescence, deep tissue subcellular uptake of insulin-Au NDs can be clearly resolved through a least-invasive harmonic generation and two-photon fluorescence (TPF) microscope. In vivo investigations on mice ear and ex vivo assays on human fat tissues conclude that cells with rich insulin receptors have higher uptake of administrated insulin. Interestingly, the insulin-Au NDs can even permeate into lipid droplets (LDs) of adipocytes. Using this newly discovered metabolic phenomenon of insulin, it is found that enlarged adipocytes in type II diabetes mice have higher adjacent/LD concentration contrast with small-sized ones in wild type mice. For human clinical samples, the epicardial adipocytes of patients with diabetes and coronary artery disease (CAD) also show elevated adjacent/LD concentration contrast. As a result, human insulin-Au nanodots provide a new approach to explore subcellular insulin metabolism in model animals or patients with metabolic or cardiovascular diseases.
\end{abstract}

C.-L. Liu, H.-C. Chen, Prof. P.-T. Chou

Department of Chemistry

National Taiwan University

Taipei, 10617 Taiwan

Fax: +886-2-369-5208

E-mail: chop@ntu.edu.tw

Prof. T.-M. Liu, T.-Y. Hsieh, H.-W. Liu, Y.-S. Chen, C.-K. Tsai Institute of Biomedical Engineering

National Taiwan University

Taipei 10617, Taiwan

Fax: +886-2-2394-0049

E-mail: tmliu@ntu.edu.tw

Prof. T.-M. Liu, Prof. C.-K. Sun

Molecular Imaging Center

National Taiwan University

Taipei 10617, Taiwan

C.-C. Chen, Prof. C.-K. Sun

Graduate Institute of Photonics and Optoelectronics

National Taiwan University

Taipei 10617, Taiwan
J.-W. Lin, Dr. T.-D. Wang

Division of Cardiology

Department of Internal Medicine

National Taiwan University Hospital

National Taiwan University College of Medicine

Taipei 10002, Taiwan

J.-W. Lin, Dr. T.-D. Wang

Cardiovascular Center and Department of Internal Medicine

National Taiwan University Hospital Yun-Lin Branch

Yun-Lin county 64041, Taiwan

R.-B. Hsu

Department of Surgery

National Taiwan University Hospital

and National Taiwan University College of Medicine

Taipei 10002, Taiwan

DOI: $10.1002 /$ smll.201201887 


\section{Introduction}

Hormone insulin, discovered by Banting and Best in 1921, [1] has long been recognized as a critical hormone that organizes the homeostasis of fuels in human body. Insulin is also directly/indirectly related to many diseases, including diabetes mellitus (DM), Alzheimer's disease, ${ }^{[2]}$ obesity ${ }^{[3]}$ and aging. ${ }^{[4]}$ Mediated by the insulin receptors on the cellular membranes, insulin stimulates the uptake of glucose and anabolic synthesis of glycogen and lipids in various tissues. Excess glucose will thus be buffered in liver, muscle, and adipose tissues for future use. On the other hand, the presence of insulin regulates the glucagon secretion, which converts glycogen in liver back to glucose. Therefore, when there are disorders in the synthesis or sensitivity of insulin, metabolic diseases like diabetes mellitus will occur. Chronically high glucose level will further result in complications such as cardiovascular diseases and kidney failure. Diagnosing the degrees and the distribution profiles of insulin resistance in vivo is a critical step toward the prevention of diabetes and its complications.

Although insulin is the up-stream signaling molecules, to evaluate insulin resistance, clinical practices mainly focus on down-stream glucose metabolism. Direct method like glucose clamp or indirect methods like glucose tolerance test and biomarker assays ${ }^{[5]}$ have been used as global measures. To image the local glucose metabolic profile in different organ or tissues, researchers commonly used radiolabeled glucose analogue fluorodeoxyglucose (FDG) in positron emission tomography (PET). ${ }^{[6]}$ Some early works attempted to employ radiolabeled insulin to correlate insulin-receptor numbers with diabetes, ${ }^{[7]}$ and measure insulin uptake in tissues. ${ }^{[8]}$ But none of these works developed a promising method in clinical practice. Moreover, due to a lack of far-red to near-infrared fluorescent insulin, it is rather difficult to probe in vivo subcellular insulin metabolism, not to mention to correlate the metabolic changes with the condition of insulin resistance.

In the past few years, fluorescent nanomaterials have gained great attention and have been intensively studied due to their unique optical, photophysical, and photochemical properties over conventional organic dyes on optical cellimaging. ${ }^{[9]}$ Although commonly used semiconductor quantum dots show promising signals on biomedical imaging, ${ }^{[10]}$ yet their high inherent cytotoxicity and self-aggregation inside live cells fatally limit the pragmatic biomedical applications. ${ }^{[11]}$ Alternatively, the fluorescent nanoclusters offer relatively low toxicity and high biocompatibility compared with semiconductor quantum dots. Among various nanoclusters, much effort has been dedicated to the study of fluorescent $\mathrm{Au}$ nanodots (NDs). ${ }^{[12]}$ The fluorescent $\mathrm{Au}$ NDs, with their ultrafine size, do not disturb the biological functions of the labeled bio-entities. It is also advantageous to use proteins as a green-chemical reducing and stabilizing agent because their complex 3D structures can withstand a wide range of $\mathrm{pH}$ conditions. ${ }^{[13]}$ With these advantages, in our latest report, we have synthesized fluorescent gold nanodots with bovine insulin and validated the intact preservation of biological functions such as lowering the glucose level. We also noticed that insulin-Au NDs could be taken up by 3 T3 mice embryonic fibroblast cells in vitro. ${ }^{[14]}$
In this study, we then advance the scope of insulin-Au NDs research by exploiting them to probe insulin metabolism in vivo. Realizing that foreign bovine or porcine insulin could result in an incidence of allergic reactions, ${ }^{[15]}$ we successfully synthesized human insulin-Au NDs with improved optical property (cf. bovine insulin-Au nanodots). ${ }^{[14]}$ Exploiting their far-red to near-infrared two-photon fluorescence, we achieved deep tissue insulin metabolic imaging with sub-cellular resolution. Using this fluorescent probe, we found the uptake of insulin is dependent on insulin receptor and insulin can even permeate into LD of adipocytes. Based on these discoveries, we further discovered that enlarged adipocytes in type II diabetic mice have higher adjacent/LD concentration contrast than small-sized ones in wild-type mice. In fresh human fattissues, epicardial adipocytes have elevated adjacent/LD concentration contrast in cardiovascular disease patients.

\section{Results and Discussion}

Detail of synthetic procedures is elaborated in the experimental section. In brief, via mixing human insulin and $\mathrm{HAuCl}_{4}$ in $\mathrm{Na}_{3} \mathrm{PO}_{4}$ buffer by stirring at $4{ }^{\circ} \mathrm{C}$ for $12 \mathrm{~h}$, reddish luminescence insulin-Au NDs were readily synthesized. The crude product was then purified by centrifugal filtration with a cutoff of $5 \mathrm{kDa}$ to obtain the insulin-Au NDs for subsequent applications. In this synthetic approach, it was found that the constant human insulin concentration of $100 \mathrm{IU} / \mathrm{mL}$, $10 \mu \mathrm{mol} \mathrm{HAuCl}_{4}(50 \mathrm{mM})$ was optimum to achieve maximum emission yield (Figure 1). The fluorescent intensity is much lower at $25 \mu \mathrm{mol} \mathrm{HAuCl}_{4}$ because the excessive $\mathrm{HAuCl}_{4}$ formed large non-emissive gold nanoparticles. For bovine insulin, as high as $25 \mu \mathrm{mol} \mathrm{HAuCl}_{4}$ were required to reach maximum emission yield. Since human insulin differs from bovine insulin by 3 amino acids (A8, A10, and B30), whether the difference is attributed to the variation of three amino acids is intriguing. This issue is not the scope of this study and hence is pending resolution. Nevertheless, the use of less reagents for the human insulin-Au NDs establishes a costeffective protocol.

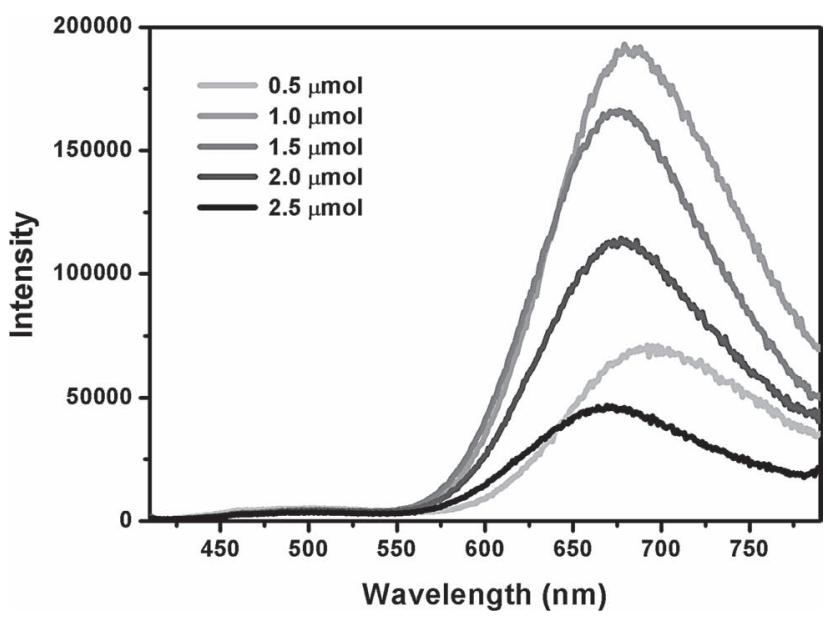

Figure 1. Fluorescence spectra of human insulin-Au NDs made with different amounts of $\mathrm{HAuCl}_{4}$ from 5 to $25 \mu \mathrm{mol}$, and insulin is 100 units for each. The excitation wavelength is at $400 \mathrm{~nm}$. 


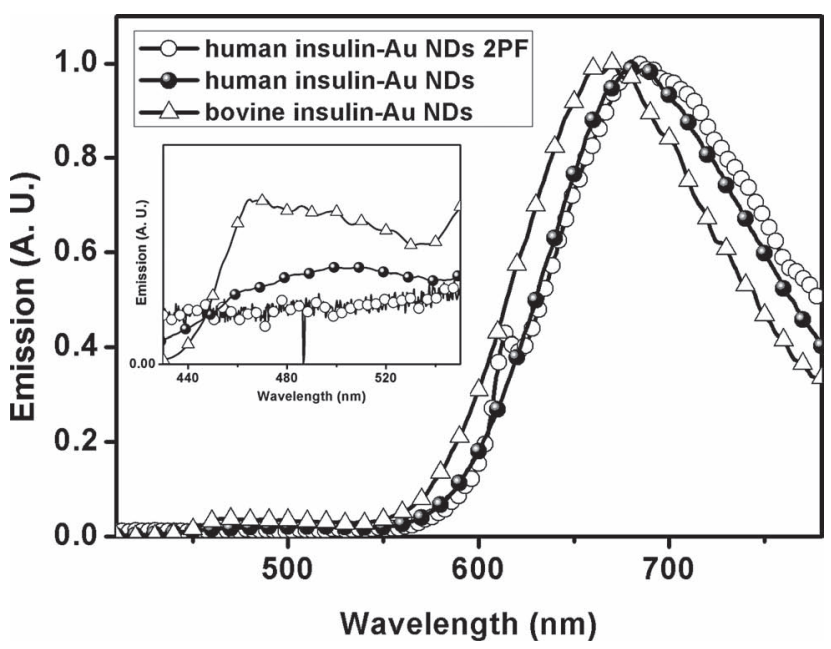

Figure 2. Fluorescence emission spectra of insulin-Au NDs by onephoton (400 nm, blue and red) and two-photon (1230 nm, black) excitation. Note: The peak at $615 \mathrm{~nm}$ in TPF spectra is the second harmonic generation signals.

As shown in Figure 2, the emission of human insulin-Au NDs, peaking at $680 \mathrm{~nm}$ with $\Phi_{\mathrm{f}} \sim 0.1$, is slightly red shifted and higher yield with respect to that reported for bovine insulin-Au NDs $\left(670 \mathrm{~nm}, \Phi_{\mathrm{f}} \sim 0.07,{ }^{[14]}\right.$ see Figure 2 for comparison). Furthermore, as shown in inset of Figure 2, the weak but noticeable $460 \mathrm{~nm}$ emission band, previously attributed to reaction intermediate of the bovine insulin-Au NDs, ${ }^{[16]}$ nearly disappears in human insulin-Au NDs. These results may manifest different amino acids composition between human and bovine insulin. Investigation on this issue is under taken and will be published elsewhere. The size (diameter) of human insulin-Au NDs, measured by high-resolution transmission electron microscopy (HR-TEM) image, is $1.04 \pm 0.12$ $\mathrm{nm}$ (see Figure 3a). This value is calculated via an average of 100 particles. Through dynamic light scattering (DLS) measurement (Figure 3b), we determine the hydrodynamic diameters of insulin and human insulin-Au NDs are $2.79 \pm 0.01$ $\mathrm{nm}$ and $5.36 \pm 0.07 \mathrm{~nm}$, respectively.

The as-prepared human insulin-Au NDs are then diluted and applied for the metabolism imaging. To investigate whether the human insulin-Au NDs are an efficient contrast
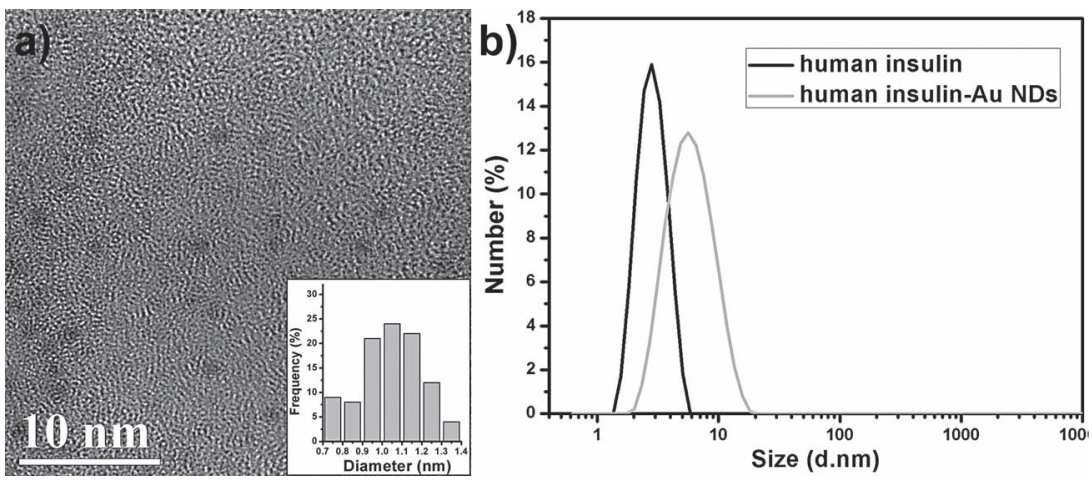

Figure 3. a) HR-TEM image and size distribution analysis of human insulin-Au NDs. b) DLS analysis of human insulin and insulin-Au NDs. agent for TPF microscopy, we then measured the two-photon fluorescence spectrum excited by a femtosecond Cr:forsterite laser. With $40 \mathrm{~mW}$ excitation, the insulin-Au NDs solution emits TPF peaks around $685 \mathrm{~nm}$ (Figure 2). Using a z-scan technique, the two-photon absorption cross section value, $\sigma$, was determined to be $\sim 5.6 \times 10^{4} \mathrm{GM}$, consistent with recent reported value. ${ }^{[17]}$ Note that the spectral power extends from $600 \mathrm{~nm}$ to $850 \mathrm{~nm}$, which is advantageous for deep tissue fluorescence imaging.

Subsequently, to demonstrate the insulin metabolic imaging capability of insulin-Au NDs, we performed nonlinear microscopy on mice ear and human fat-tissues. Compared with typical histology of mice ear, ${ }^{[18]}$ in vivo third harmonic generation (THG) imaging can clearly resolve the sebaceous glands, vessels, adipocytes, elastin fibers, and chondrocytes in elastic cartilage (Figure S1). ${ }^{[19]}$ The characteristic lipid droplets and squeezed cytoplasm (indicated by white arrow) of adipocytes can be resolved and identified (Figure S1b). In BALB/c mice (wild-type), the cell diameter of adipocytes is typically around $32 \mu \mathrm{m}$. On the other hand, the in vivo second harmonic generation ( $\mathrm{SHG}$ ) imaging reveals the distribution of collagen networks. Except for hairs in sebaceous gland, no TPF contrast can be observed in ear sectioning images.

After subcutaneous injection of insulin-Au NDs, as we expected, the TPF contrast of insulin-Au NDs can be clearly observed even at deep cartilage tissues with chondrocytes (Figure 4a-c). As shown in Figure S2, after 800 s continuous observation, the interstitial TPF intensity decayed to $60 \%$ of initial level, which corresponds to a 26 minutes half-life. ${ }^{[20]}$ The retention time is long enough for the observation of cellular response to insulin-Au NDs. By taking the average TPF intensity outside over inside the cells, defined as the concentration contrasts, we were able to evaluate the relative amount of insulin uptake cross cellular membranes. Since the axial-resolution of the TPF imaging at deep tissue could be degraded to $2 \mu \mathrm{m}$, to avoid ambiguity, the regions selected for the integration of TPF yields were kept $5 \mu \mathrm{m}$ away from cellular boundaries. As shown in Figure 4d-f, sebaceous gland cells has high ( 10) adjacent/cytoplam (Adj/Cyto) concentration contrast while chondrocytes has a low value of 1.6. The decreased contrast was related to the fact that there are insulin receptors on the membrane of chondrocytes. ${ }^{[21]}$ When insulin docks on the receptor, the insulin-bound receptor can be internalized to cytoplasm and other organelles. ${ }^{[22]}$ In our previous work, ${ }^{[14]}$ the blood glucose-lowering activity of insulin-Au NDs in $\mathrm{C} 57 \mathrm{BL} / 6 \mathrm{~J}$ mice is comparable to the commercialized agents. The results indicate that the interaction between insulin-Au NDs and the insulin receptor remains effective. Accordingly, the insulin receptor should play a role in the internalization of insulin-Au NDs. Nevertheless, the actual uptake mechanism is still pending resolution.

Adipocyte is another cell type that has rich insulin receptors. The insulin can stimulate the uptake of glucose into adipocytes and the synthesis of triglyceride 


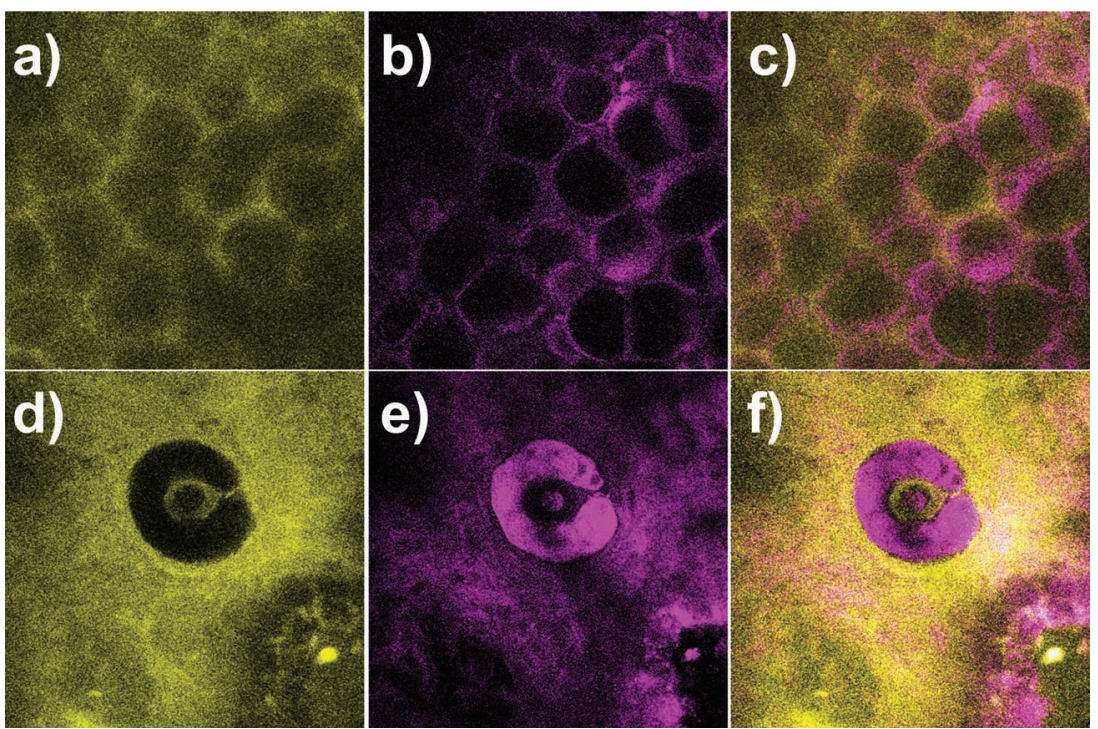

Figure 4. The a,d) TPF (yellow color), b,e) THG (magenta color), and c,f) combined images of chondrocytes (upper row) and sebaceous gland (bottom row) in the ear of mice. Fields of view: $240 \times 240 \mu \mathrm{m}$.

from fatty acids. The characteristic lipid droplet in adipocytes is the storage of triglyceride. It has been shown that accumulation and hypertrophy of subcutaneous adipocytes is one of the signatures in the fat tissues of diabetes mellitus. ${ }^{[23]}$ In BALB/c mice, according to the TPF and THG images (Figure S2 and
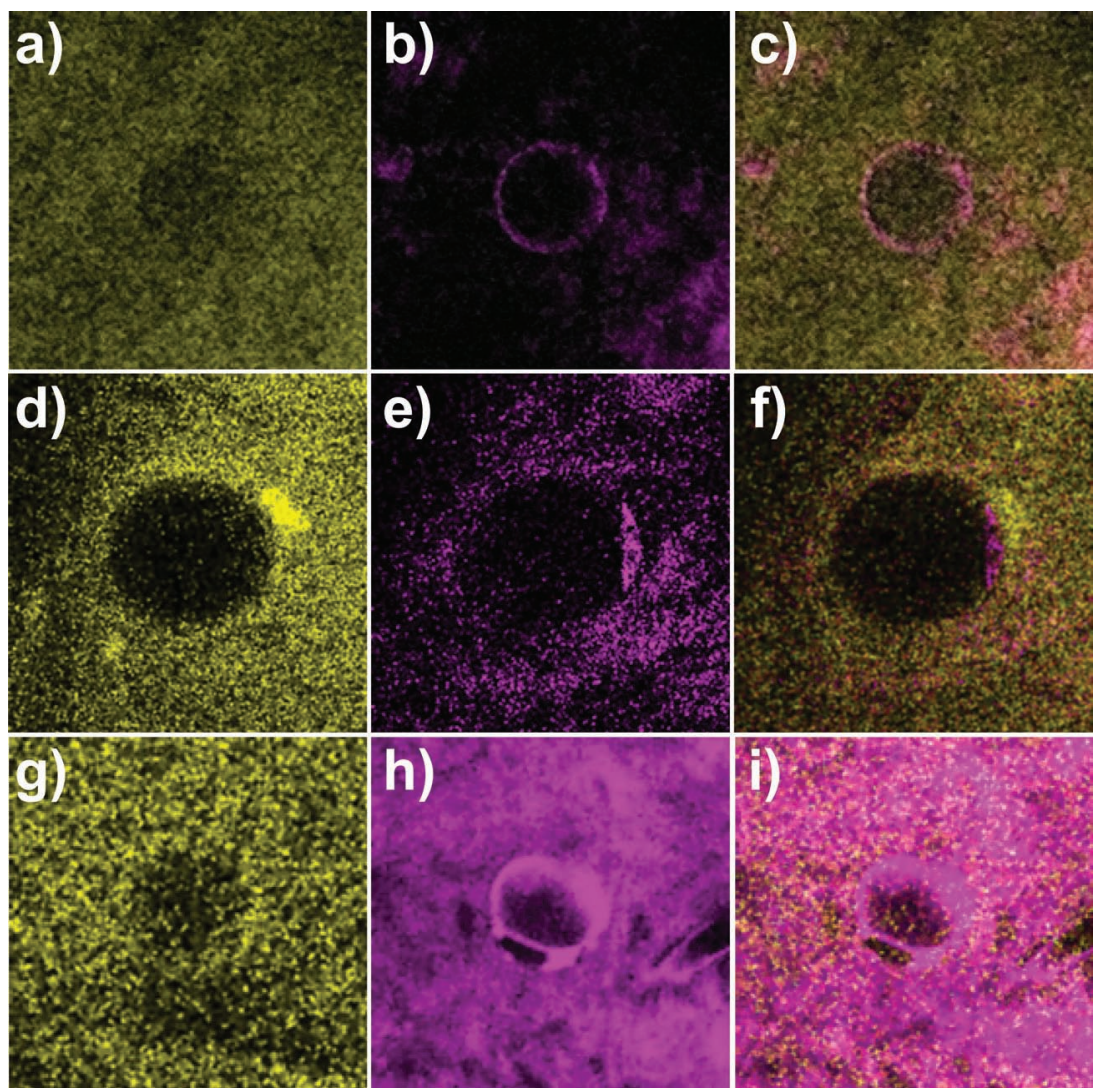

Figure 5. The a,d,g) TPF (yellow color), b,e,h) THG (magenta color), and c,f,i) combined images of adipocytes in BALB/c mice (upper row), type II diabetic mice (middle row), and C57BL/6-c2 mice (bottom row). Adipocytes were in the ear of mice. Fields of view: $80 \times 80 \mu \mathrm{m}$.
Figure 5a-c), Adj/Cyto contrast were typically $1.17-1.22$ (see Table $\mathbf{1}$ ), which is comparable with those of chondrocytes. Interestingly, the concentration contrast of adjacent one over that in intracellular lipid droplet was not high (around 1.67, Table 1). It is worthy to note that no previous works have ever reported such insulin internalization by LDs. We also double checked and confirmed this LD internalization on differentiated 3T3-L1 adipocytes (see Supporting Information Figure S3). The mechanism of uptake could be due to the caveolae-mediated endocytosis after insulin binding with receptors. ${ }^{[24]}$ Several reports have indicated that caveolin in caveolae can be delivered to lipid droplet through caveosome. ${ }^{[25]}$ Actual mechanism of insulin internalization in LD requires further studies to confirm. In yet another approach, for adipocytes in type II diabetic mice, the diameters can be as large as $50 \mu \mathrm{m}$ (Figure $5 \mathrm{~d}-\mathrm{f}$ ). The corresponding Adj/Cyto and Adj/LD concentration contrast was increased to 1.54 and 7.14, respectively. A much smaller adipocyte in the same diabetic mice $($ diameter $=34 \mu \mathrm{m})$ showed a decreased Adj/LD contrast of 2.5 (see Table 1). This preliminary test suggests that the enlarged adipocytes of diabetic mice have higher Adj/Cyto and Adj/LD contrast than those in wild-type (BALB/c strain). Such physiological response of insulin-Au NDs has a correlation with the size of adipocytes.

To check if the Adj/Cyto and Adj/LD contrasts of insulin-Au NDs in adipocytes are dependent on the strain of mice, we also purchased albino mice carrying a mutation in tyrosinase (C57BL/6-c2J). The albino mice of the $\mathrm{C} 2 \mathrm{~J}$ albino strain was imported from the Jackson Laboratory. The results (Figure $5 \mathrm{~g}$-i) showed that the Adj/Cyto and Adj/LD concentration contrast were 1.12-1.22 and 1.85-2.13, respectively. Obviously, the contrast values did not have significant change with the strain of mice and they were also lower than the contrast of diabetic mice.

To validate whether this increased concentration contrasts still holds for human adipocytes, we performed similar assay on fresh fat-tissues taken from normal, coronary artery disease (CAD), and CAD+DM patients right after surgery (within $3 \mathrm{~h}$ ). It has been noticed that the enlargement of epicardial and pericardial fat is an alarm for obesity-related cardiac dysfunction. Moreover, several reports indicated that cardiovascular disease is highly related to the amount of adipose tissue around the heart. ${ }^{[26]}$ Disorder of insulin metabolism might occur in such disease-related 
Table 1 In vivo imaging insulin-Au NDs concentration contrast for different sizes of adipocytes.

\begin{tabular}{lccc}
\hline Mice Strain & Diameter $[\mu \mathrm{m}]$ & Adj/LD & Adj/Cyto \\
\hline \multirow{2}{*}{ BALB/c } & 20 & 1.61 & 1.17 \\
& 25 & 1.67 & 1.22 \\
KK-A $/$ Ta Jcl & 34 & 2.50 & 1.56 \\
C57BL/6-C2] & 50 & 7.14 & 1.54 \\
& 23 & 1.85 & 1.12 \\
& 35 & 2.13 & 1.22 \\
\hline
\end{tabular}

${ }^{\text {a) }} \mathrm{Adj} / \mathrm{LD}$ : adjacent insulin-Au NDs concentration over that in lipid droplet; ${ }^{\mathrm{b})} \mathrm{Adj} / \mathrm{Cyto}$ : adjacent insulin-Au NDs concentration over that in cytoplasm.

adipocytes. According to the IRB protocol, the epicardial fat-tissues were incubated with DMEM medium to preserve their bio-activities. For the microscopy observation, we placed them on a bottom-glass petri-dish and mounted the dish in a microscope incubator with $37{ }^{\circ} \mathrm{C}$ water bath. The focusing objective had a water contact with bottom glass petri-dish, and we also heated it to $37^{\circ} \mathrm{C}$ to avoid local cooling. This microincubator system was mounted on an inverted microscope (IX71, Olympus) and the experimental setup was similar to that in previous animal experiments. Through THG microscopy, the boundary tomography of adipocytes was observed and their sizes can thus be measured (Figure S4a). Bubbles of adipocytes were connected by collagen fibers winding around them (Figure S4a, green color). For each adipocyte, we scanned through it with THG sectioning images and evaluate the long-axis at the one with largest cross section area. The size histogram of 100-adipocytes from tissues showed a peak diameter at 70-80 $\mu \mathrm{m}$ (Figure 6), which agrees with normal size in human fat-tissues. ${ }^{[27]}$ Incubating each tissue with insulin-Au NDs for 10 minutes, at steady state, we then imaged their uptake profiles through TPF contrast. In a typical image on fat-tissue of a CAD patient, $30 \mu \mathrm{m}$ adipocyte had $\mathrm{Adj} / \mathrm{LD}$ concentration contrast of 5.0 (Figure S4b, indicated by a white arrow). In comparison, the Adj/LD concentration contrasts increased to 10 for large ones $(>50 \mu \mathrm{m})$.

Using this evaluation platform, we investigated fat-tissues from (1) normal, (2) CAD, and (3) CAD+DM patients. For normal patient, statistical results on each 100 adipocytes (Figure 7a) showed an evident trend that 20-80 $\mu \mathrm{m}$ sized adipocytes have their Adj/LD contrast below 4. Only for

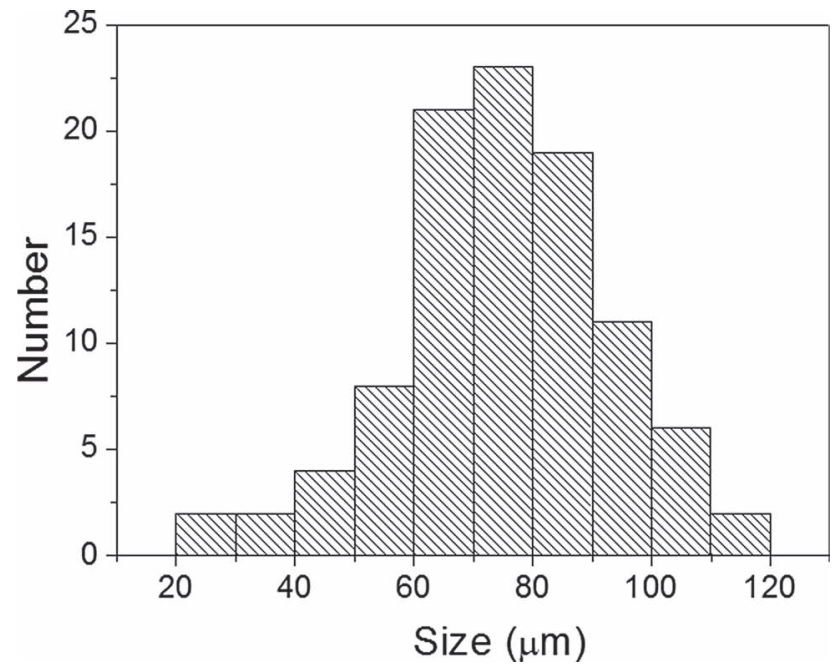

Figure 6. The size histogram of 100 adipocytes in the fat-tissues of a CAD patient.

adipocytes with sizes larger than $80 \mu \mathrm{m}$, the Adj/LD contrasts were raised above 4 . In contrast, for CAD or CAD+DM patients, small sized $(<40 \mu \mathrm{m})$ adipocytes already have a high Adj/LD contrasts above 4 and most of the other adipocytes have their Adj/LD contrasts elevated above 8 (Figure 7b,c). Especially for $60-80 \mu \mathrm{m}$ adipocytes, in comparison with normal ones, the Adj/LD contrasts of CAD and CAD+DM patients were significantly raised more than 3 times (from 3 to 11.7 and 10.6, respectively). Regarding the Adj/Cyto concentration contrasts, they ranged from 1 to 2 and only change slightly with patients. (Figure 7, grey bars). Together with the results of mice, our preliminary investigation suggests that, in the disease context of DM or CAD, adipocytes have elevated Adj/LD concentration contrast. The elevation can be more than 3 times, which is significant enough for developing diagnosis applications.

\section{Conclusion}

In summary, we have successfully synthesized fluorescent human insulin-Au nanodots and in vivo imaged their metabolic uptake in different types of cells. In mice ear, cells with insulin receptors promote their uptake of insulin-Au
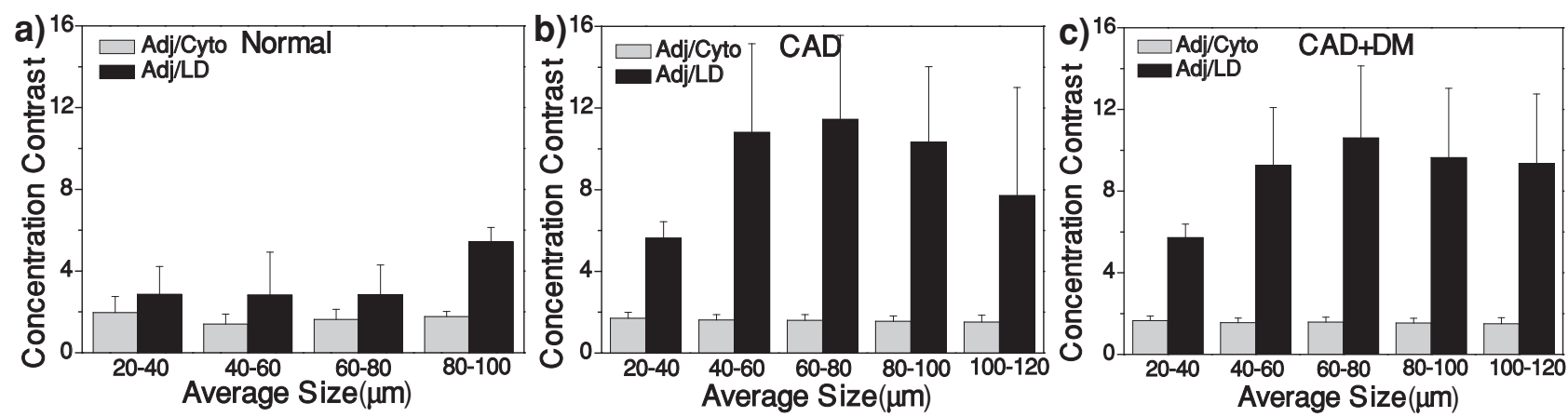

Figure 7. Statistics on the concentration contrast of insulin-Au NDs for cytoplasm (Adj/Cyto, grey bars) and lipid droplet (Adj/LD, black bars) of a) normal b) $C A D$ c) CAD+DM human adipocytes. Several ranges of sizes were classified. 
NDs. For adipocytes, a permeation of insulin into LDs was observed, which have not been reported before. Using this newly discovered metabolism of insulin in vivo, we found adipocytes in the disease context of DM or CAD have elevated $\mathrm{Adj} / \mathrm{LD}$ concentration contrast. The degrees of elevation for $60-80 \mu \mathrm{m}$ adipocytes were more than 3 times, which is significant enough for developing diagnosis applications. These results therefore demonstrate a new approach to probe subcellular insulin metabolism in the context of cardiovascular diseases or metabolic diseases like insulin resistance. For example, it can be used to investigate how size of adipocyte affects the physiological sensitivity to insulin. ${ }^{[28]}$ Correlation between sub-cellular insulin metabolism and global insulin resistance can also be explored. This also leads to a fundamental challenge regarding why and how adipocytes have elevated $\mathrm{Adj} / \mathrm{LD}$ concentration contrast in $\mathrm{CAD}$ and $\mathrm{DM}$ contexts and what is the insight of its relation to diseases. Furthermore, recent reports also indicate that fluorescent insulin-Au NDs reveal X-ray contrast in computer tomography $(\mathrm{CT}){ }^{[14,29]}$ Combined the intact bio-activity, fluorescence imaging and contrast in X-ray CT, insulin-Au NDs may act as a multi-functional contrast agent to image insulin metabolism all the way from sub-cellular scale, tissues level, to whole body range.

\section{Experimental Section}

Synthesis of Human Insulin-Au NDs: Humulin R was purchased from Eli Lilly. Hydrogen tetrachloroaurate (III) trihydrate $\left(\mathrm{HAuCl}_{4} \cdot 3 \mathrm{H}_{2} \mathrm{O}\right)$ and sodium hydroxide were obtained from Acros. Reagent solutions were prepared using Milli-Q water (Millipore Co.). All glassware used in the experiment was cleaned with freshly prepared aqua regia $\left(\mathrm{HCl}: \mathrm{HNO}_{3}\right.$ volume ratio $\left.=3: 1\right)$ and rinsed thoroughly in ultrapure water prior to use. In a typical experiment, Humulin R was first purified by centrifugal filtration (4000 g) twice for 30 min with a cutoff of $3 \mathrm{kDa}$ (Millopore) using $0.01 \mathrm{M} \mathrm{Na}_{3} \mathrm{PO}_{4}$ buffer ( $\mathrm{pH}$ 10.4). Aqueous $50 \mathrm{mM} \mathrm{HAuCl}$ solution was adjusted to $\mathrm{pH} 10.4$ with $\mathrm{NaOH}$. Then $\mathrm{HAuCl}_{4}$ solution $(200 \mu \mathrm{L}, 50 \mathrm{mM})$ was added to insulin ( $1 \mathrm{~mL}, 100 \mathrm{IU} / \mathrm{mL}$ ). By reacting with insulin for $24 \mathrm{~h}$ at $4{ }^{\circ} \mathrm{C}$, red-emissive insulin-Au nanodots were generated. Then the crude product was purified by centrifugal filtration $(4000 \mathrm{~g})$ for 30 min with a cutoff of $5 \mathrm{kDa}$ for subsequent applications. High resolution images of $\mathrm{Au}$ NDs were obtained with a transmission electron microscope (TEM, JEM-2100F, JEOL) operated at $200 \mathrm{kV}$ in order to determine their shape, dimension and size distribution. The specimen was prepared by drop-casting the Au NDs suspension on a Cu-grid-supported quantifoil. By observing the casted materials at the hole area of the supporting film, background-less image was then obtained.

Spectral Measurements: Steady-state absorption and emission spectra of insulin-Au NDs were recorded with a Hitachi U-3310 spectrophotometer and an Edinburgh FS920 fluorimeter respectively. The spectral responses of excitation and emission of the fluorimeter were both calibrated. The emission quantum yield of insulin-Au NDs was determined by a comparison method, in which the DCM dye (4-(dicyanomethylene)-2-methyl-6-(4dimethylaminostyryl)-4H-pyran) solution in methanol with known quantum yield of $\sim 0.44$ served as a standard.
Concentration Dependent Fluorescence: To investigate the concentration dependence of fluorescence yield from insulin-Au NDs, we used a $1.5 \mathrm{~W}$ femtosecond Ti:sapphire laser (Mira, Coherent) and a $\beta$-barium borate (BBO) to obtain $400 \mathrm{~nm}$ excitation pulses with $200 \mathrm{~mW}$ average power and $250 \mathrm{fs}$ pulse width. The laser pulse was focused by a lens $(f=3 \mathrm{~cm})$ into the solution held in a $1 \mathrm{~cm}$ thick cuvette. The fluorescence was side-collected by another $3-\mathrm{cm}$ lens and the excitation signal was highly attenuated by a combination of color filters. Then the red fluorescence signal was detected by a photomultiplier tube (R928p, Hamamatsu). Using an acousto-optic modulator, the pump beam was modulated at a frequency of $100 \mathrm{kHz}$ and the fluorescence signals were lock-in detected (SR844, Stanford Research). As shown in Figure S5, the concentration dependence of fluorescence yield (in $\mu \mathrm{V}$ ) is linear $(R=0.9948)$ and the concentration as low as $170 \mathrm{pM}$ can still be detected with sufficient signal to noise ratio.

In vivo Nonlinear Microscopy System: The in vivo nonlinear microscope is excited by a femtosecond $\mathrm{Cr}$ :forsterite laser with 100 fs pulse-width, $110 \mathrm{MHz}$ pulse repetition-rate, and $1230 \mathrm{~nm}$ central wavelengths. ${ }^{[30]}$ The nonlinear contrasts include TPF, second-harmonic-generation (SHG), and third-harmonic-generation (THG). The nature of signal generation provides sectioning capability with sub-micron spatial resolution. Compared with other femtosecond laser sources, the Cr:forsterite laser based nonlinear microscope has least invasiveness, ${ }^{[31]}$ highest penetration depth $(>350 \mu \mathrm{m}),{ }^{[32]}$ and extra THG modality that are capable of imaging the lipids ${ }^{[33]}$ and elastin. ${ }^{[19]}$ The laser beam is directed to a scanning units (FluoView 300, Olympus) cascaded with an upright microscope (IX51, Olympus). After the $60 \times \mathrm{NA}=1.2$ water immersion focusing objective (UPLSAPO 60XW, Olympus), the excitation power can reach $70 \mathrm{~mW}$. The generated TPF, SHG, and THG signals will be epi-collected with the same objective. The TPF signals will pass through the $665 \mathrm{~nm}$ long-pass dichroic beam splitter and detected by a photomultiplier tube (PMT) inside the scanning unit. The SHG and THG signals will be reflected by $665 \mathrm{~nm}$ long-pass dichroic beam splitter and further separated by another $495 \mathrm{~nm}$ long-pass dichroic beamsplitter. They were finally detected by other two PMTs equipped with $610 \mathrm{~nm}$ and $410 \mathrm{~nm}$ band-pass filters, respectively. Laser scanned images of all three contrasts will be recorded with $3 \mathrm{~s}$ integration time and reconstructed into a $512 \times 512$ pixels images.

Mice Experiment: The animals used for in vivo microscopy observation are BALB/C and KK-A $\mathrm{Y} / \mathrm{Ta}$ Jcl. The BALB/c female mice aged 8 weeks were purchased from Animal Center of National Taiwan University Hospital. All mice were acclimatized in plastic cages. The body weight was $25 \mathrm{~g}$ amid the experiment. Male 5-week old KK-A $\mathrm{Y} / \mathrm{Ta}$ Jcl mice were obtained from CLEA Japan. The mice were housed in cages located in a room with controlled temperature and humidity. After 11 weeks, their body weights were increased to $45 \mathrm{~g}$. It's a good model of obesity-associated type II diabetes mellitus (DM) with insulin resistance. ${ }^{[34]}$ For the static observation of mice under in vivo nonlinear microscope, we used isoflurane inhalation anesthetics for its effectiveness, lack of sideeffects and rapid wash-out, especially in consecutive time-course imaging. It supplies oxygen during whole anesthetic periods and good for rapid anesthetic recovery. Anesthesia is maintained with isoflurane vaporized at concentrations of up to $4 \%$ in the induction phase, at $0.8-1.5 \%$ during prolonged experimental observations. We monitor reflexes and vital signs (94-163 breaths/min, 
$325-780$ beats $/ \min , 37.5^{\circ} \mathrm{C}$ ) of the anesthetized mice and maintain the body temperature with small warm bag during whole anesthetic periods throughout recovery. insulin-Au NDs solution $(10 \mathrm{mg} / \mathrm{mL})$ in $20 \mu \mathrm{L}$ volume was interstitially injected into the mice ear via $30 \mathrm{G}$ insulin syringe. A cotton-tipped applicator was then pressed on the site of puncture to prevent the leaking from the skin. All mice used for experiments received humane care in compliance with the institution's guidelines for maintenance and use of laboratory animals in research. All of the experimental protocols involving live animals were reviewed and approved (Case number 20110331) by the Animal Experimentation Committee of National Taiwan University Hospital. All mice were acclimatized in plastic cages and taken care of by the animal center.

Two-Photon Absorption Cross Section Measurement: The open aperture Z-scan experiments were conducted with the experimental setup and procedure described in literature. ${ }^{[35]}$ In this study, a mode-locked Ti:sapphire laser (Tsunami, Spectra Physics) was coupled to a regenerative amplifier that generated $\sim 150 \mathrm{fs}$, $1 \mathrm{~mJ}$ pulses (800 nm, $1 \mathrm{kHz}$, Spitfire Pro, Spectra Physics). The pulse energy, after proper attenuation, was reduced to $0.75-1.5 \mu \mathrm{J}$ and the repetition rate was further reduced to $20 \mathrm{~Hz}$ to eliminate excited-state absorption (ESA). After passing through an $\mathrm{f}=30 \mathrm{~cm}$ lens, the laser beam was focused through a $2.00 \mathrm{~mm}$ cell filled with the sample solution $\left(3.1 \times 10^{-4}-1.1 \times 10^{-3} \mathrm{M}\right)$ and the beam radius at the focal position was $5.09 \times 10^{-3} \mathrm{~cm}$. When the sample cell was translated along the beam direction (z-axis), the transmitted laser intensity was detected by a photodiode (PD-10, Ophir). The TPA-induced decrease in transmittance, $T(\mathrm{z})$, can be fitted with Equations (1) and (2), in which the TPA coefficient $(\beta)$ is incorporated: ${ }^{[36]}$

$T(z)=\sum_{n=0}^{\infty} \frac{(-q)^{n}}{(n+1)^{3 / 2}}$

$q=\frac{B I_{0} L}{1+\frac{z^{2}}{z_{0}^{2}}}$

where $\mathrm{n}$ is an integer number from 0 to $\infty$ and has been truncated at $n=1000, L$ is the sample length, $I_{0}$ is the input intensity, z represents the sample position with respect to the focal point, and $z_{0}$ denotes the diffraction length of the incident beam (Rayleigh range). After obtaining $\beta$, TPA cross-section $\left(\sigma_{2}\right)$ can be deduced with Equation (3):

$\beta=\frac{\sigma_{2} N_{A} d \times 10^{-3}}{h v}$

where $N_{A}$ is the Avogadro's constant, $d$ is the sample concentration, and $h v$ is the incident photon energy.

Two-Photon Fluorescence Measurements: To measure the TPF spectrum of human insulin-Au NDs, we used the same objective ( $60 \mathrm{X}$ water immersion, $N A=1.2)$ to focus excitation beam and detected the spectral signals with thermal-electric cooled chargecouple-device (CCD) spectrometer. The temperature was cooled down to $-60{ }^{\circ} \mathrm{C}$ for higher signal to noise ratio. The multiphoton signals generated from insulin-Au NDs solutions were reflected by a $865 \mathrm{~nm}$-edged dichroic beam splitter and focused onto the slit of spectrometer by a lens with $10 \mathrm{~cm}$ focal distance. The open width of slit is $200 \mu \mathrm{m}$ and the integration time is $60 \mathrm{~s}$. All the spectra were calibrated by a $\mathrm{Hg}(\mathrm{Ne})$ lamp.
Human Fat-tissues: The tissue samples of coronary artery disease (CAD) patients were taken in Off Pump Coronary Artery Bypass method of surgery. The samples of normal patients were taken from the surgery of Mitral Valve Replacement. Both of them were taken at the National Taiwan University Hospital. The experimental protocol was approved by the institutional review board (IRB) of National Taiwan University Hospital under the case number of 200812090R. Written informed consent was obtained from the participant. Clinical information and current cardiovascular medication use was documented using a standardized questionnaire. Adipose tissue biopsy samples were obtained before the initiation of cardiopulmonary bypass. All the specimens were rinsed with $1 \times$ PBS buffer. After removal of visible blood vessels, part of the sample were weighed, cut into small pieces $\left(\sim 2 \mathrm{~mm}^{3}\right)$, and transferred into a glass bottom petri dish. According to tissue weight, serum-free DMEM $(2 \mathrm{~mL} / \mathrm{g}$ ) were added to the well and brought to our imaging platform for the assay with insulin-Au NDs.

\section{Supporting Information}

Supporting Information is available from the Wiley Online Library or from the author.

\section{Acknowledgements}

This study was supported by National Health Research Institutes under NHRI-EX100-9936EI and National Science Council of Taiwan. We thank Prof. Jing-Jong Shyue for TEM estimation.

[1] F. G. Banting, C. H. Best, J. Lab. Clin. Med. 1922, 7, 251-266.

[2] S. M. de la Monte, J. R. Wands, J. Alzheimer's Dis. 2005, 7, 45-61.

[3] S. E. Kahn, R. L. Hull, K. M. Utzschneider, Nature 2006, 444, 840-846.

[4] M. Tatar, A. Bartke, A. Antebi, Science 2003, 299, 1346-1351.

[5] W. E. Gall, K. Beebe, K. A. Lawton, K. P. Adam, M. W. Mitchell, P. J. Nakhle, J. A. Ryals, M. V. Milburn, M. Nannipieri, S. Camastra, A. Natali, E. Ferrannini, PLoS One 2010, 5, e10883.

[6] L. M. Voipiopulkki, P. Nuutila, M. J. Knuuti, U. Ruotsalainen, M. Haaparanta, M. Teras, U. Wegelius, V. A. Koivisto, J. Nucl. Med. 1993, 34, 2064-2067.

[7] a) J. M. Olefsky, G. M. Reaven, J. Clin. Invest. 1974, 54, 13231328; b) T. J. Robinson, J. A. Archer, K. K. Gambhir, V. W. Hollis Jr, L. Carter, C. Bradley, Science 1979, 205, 200-202.

[8] A. Holmang, P. Bjorntorp, B. Rippe, Am. J. Physiol. 1992, 263, H1170-1176.

[9] W. Jiang, S. Mardyani, H. Fischer, W. C. W. Chan, Chem. Mater. 2006, 18, 872-878.

[10] V. Patel, A. A. Bhirde, J. Gavard, G. F. Zhang, A. A. Sousa, A. Masedunskas, R. D. Leapman, R. Weigert, J. S. Gutkind, J. F. Rusling, ACS Nano 2009, 3, 307-316.

[11] J. F. Weng, J. C. Ren, Curr. Med. Chem. 2006, 13, 897-909.

[12] a) S. Link, M. A. El-Sayed, T. G. Schaaff, R. L. Whetten, Chem. Phys. Lett. 2002, 356, 240-246; b) G. H. Woehrle, L. O. Brown, J. E. Hutchison, J. Am. Chem. Soc. 2005, 127, 2172-2183; C) J. M. Abad, L. E. Sendroiu, M. Gass, A. Bleloch, A. J. Mills, D. J. Schiffrin, J. Am. Chem. Soc. 2007, 129, 12932-12933; 
d) P. D. Jadzinsky, G. Calero, C. J. Ackerson, D. A. Bushnell, R. D. Kornberg, Science 2007, 318, 430-433; e) M. Eichelbaum, B. E. Schmidt, H. Ibrahim, K. Rademann, Nanotechnology 2007, 18, 355702.

[13] a) A. Retnakumari, S. Setua, D. Menon, P. Ravindran, H. Muhammed, T. Pradeep, S. Nair, M. Koyakutty, Nanotechnology 2010, 21, 055103; b) R. Zhou, M. Shi, X. Chen, M. Wang, H. Chen, Chem. Eur. J. 2009, 15, 4944-4951; c) J. Xie, Y. Zheng, J. Y. Ying, J. Am. Chem. Soc. 2009, 131, 888-889; d) W. Y. Chen, J. Y. Lin, W. J. Chen, L. Y. Luo, E. W. G. Diau, Y. C. Chen, Nano medicine 2010, 5, 755-764; e) L. Xu, C. J. Sun, H. Yang, Y. Yuan, X. Tian, L. M. Wang, Y. Guo, J. L. Lei, N. Gao, G. J. Anderson, X. J. Liang, C. Y. Chen, Y. L. Zhao, G. J. Nie, J. Am. Chem. Soc. 2011, 133, 8617-8624; f) X. Le Guevel, N. Daum, M. Schneider, Nanotechnology 2011, 22, 275103; g) X. R. Zhang, F. Wen, Y. H. Dong, L. Feng, S. Wang, S. C. Zhang, Anal. Chem. 2011, 83, 1193-1196.

[14] C. L. Liu, H. T. Wu, Y. H. Hsiao, C. W. Lai, C. W. Shih, Y. K. Peng, K. C. Tang, H. W. Chang, Y. C. Chien, J. K. Hsiao, J. T. Cheng, P. T. Chou, Angew. Chem. Int. Ed. 2011, 50, 70567060.

[15] L. Heinzerling, K. Raile, H. Rochlitz, T. Zuberbier, M. Worm, Allergy 2008, 63, 148-155.

[16] H. Wei, Z. Wang, L. Yang, S. Tian, C. Hou, Y. Lu, Analyst 2010, 135, 1406-1410.

[17] a) C. L. Liu, M. L. Ho, Y. C. Chen, C. C. Hsieh, Y. C. Lin, Y. H. Wang, M. J. Yang, H. S. Duan, B. S. Chen, J. F. Lee, J. K. Hsiao, P. T. Chou, J. Phys. Chem. C 2009, 113, 21082-21089; b) P. N. Day, K. A. Nguyen, R. Pachter, J. Chem. Theory Comput. 2010, 6, 2809-2821.

[18] Q. C. Lin, A. B. Clark, S. D. McCulloch, T. Yuan, R. T. Bronson, T. A. Kunkel, R. Kucherlapati, Cancer Res. 2006, 66, 87-94.

[19] C. K. Sun, C. H. Yu, S. P. Tai, C. T. Kung, I. J. Wang, H. C. Yu, H. J. Huang, W. J. Lee, Y. F. Chan, Opt. Express 2007, 15, 11167-11177.

[20] J. C. Cresto, R. L. Lavine, M. L. Buchly, J. C. Penhos, S. J. Bhathena, L. Recant, Acta Physiol. Lat. Am. 1977, 27, 7-15.

[21] S. C. Rosa, A. T. Rufino, F. Judas, C. Tenreiro, M. C. Lopes, A. F. Mendes, Osteoarth. Cart. 2011, 19, 719-727.

[22] a) M. E. V. Mora, A. Scarfone, M. Calvani, A. V. Greco, G. Mingrone, J. Am. Coll. Nutr. 2003, 22, 487-493; b) P. Gorden, J. L. Carpentier, P. Freychet, A. Lecam, L. Orci, Science 1978, 200, 782-785; c) P. Berhanu, J. M. Olefsky, P. Tsai, P. Thamm, D. Saunders, D. Brandenburg, Proc. Natl. Acad. Sci. USA 1982, 79, 4069-4073.

[23] a) M. M. Ibrahim, Obes. Rev. 2010, 11, 11-18; b) S. E. Kahn, M. Cnop, M. J. Landchild, J. Vidal, P. J. Havel, N. G. Knowles, D. R. Carr, F. Wang, R. L. Hall, E. J. Boyko, B. M. Retzlaff,
C. E. Walden, R. H. Knopp, Diabetes 2002, 51, 10051015.

[24] S. Fagerholm, U. Ortegren, M. Karlsson, I. Ruishalme, P. Stralfors, Plos One 2009, 4, e5985.

[25] a) R. G. Parton, K. Simons, Nat. Rev. Molec. Cell Biol. 2007, 8, 185-194; b) N. Anderson, J. Borlak, Pharmacol. Rev. 2008, 60, 311-357.

[26] a) A. Xu, P. M. Vanhoutte, Am. J. Physiol.-Heart C. 2012, 302, H1231-H1240; b) D. M. Jaworski, O. Sideleva, H. M. Stradecki, G. D. Langlois, A. Habibovic, B. Satish, W. G. Tharp, J. Lausier, K. Larock, T. L. Jetton, M. Peshavaria, R. E. Pratley, Endocrinology 2011, 152, 1300-1313; c) G. A. Rosito, J. M. Massaro, U. Hoffmann, F. L. Ruberg, A. A. Mahabadi, R. S. Vasan, C. J. O'Donnell, C. S. Fox, Circulation 2008, 117, 605-613; d) S. Eroglu, L. E. Sade, A. Yildirir, U. Bal, S. Ozbicer, A. S. Ozgul, H. Bozbas, A. Aydinalp, H. Muderrisoglu, Nutr. Metab. Cardiovasc. Dis. 2009, 19, 211-217.

[27] T. Skurk, C. Alberti-Huber, C. Herder, H. Hauner, J. Clin. Endocrinol. Metab. 2007, 92, 1023-1033.

[28] a) J. O’Connell, L. Lynch, T. J. Cawood, A. Kwasnik, N. Nolan, J. Geoghegan, A. McCormick, C. O'Farrelly, D. O'Shea, PLoS One 2010, 5, e9997; b) E. Ravussin, M. Pasarica, Y. D. Tchoukalova, L. K. Heilbronn, X. B. Fang, J. B. Albu, D. E. Kelley, S. R. Smith, L. A. A. R. Group, Obesity 2009, 17, 1976-1978; c) K. Azuma, L. K. Heilbronn, J. B. Albu, S. R. Smith, E. Ravussin, D. E. Kelley, Am. J. Physiol. Endocrinol. Metab. 2007, 293, E435-E442.

[29] C. Zhou, M. Long, Y. Qin, X. Sun, J. Zheng, Angew. Chem. Int. Ed. 2011, 50, 3168-3172.

[30] S. W. Chu, I. H. Chen, T. M. Liu, P. C. Chen, C. K. Sun, B. L. Lin, Opt. Lett. 2001, 26, 1909-1911.

[31] S. Y. Chen, H. Y. Wu, C. K. Sun, J. Biomed. Opt. 2009, 14, 060505.

[32] T. Yasui, Y. Takahashi, M. Ito, S. Fukushima, T. Araki, Appl. Opt. 2009, 48, D88-95.

[33] E. Beaurepaire, D. Debarre, W. Supatto, A. M. Pena, A. Fabre, T. Tordjmann, L. Combettes, M. C. Schanne-Klein, Nat. Methods 2006, 3, 47-53.

[34] N. Yamada, M. Suzuki, H. Kakuta, A. Takahashi, H. Shimano, K. Tada-lida, T. Yokoo, R. Kihara, J. Atheroscler. Thromb. 2005, 12, 77-84.

[35] a) M. Sheikbahae, A. A. Said, T. H. Wei, D. J. Hagan, E. W. Vanstryland, IEEE J. Quantum Electron. 1990, 26, 760-769; b) J. Swiatkiewicz, P. N. Prasad, B. A. Reinhardt, Opt. Commun. 1998, 157, 135-138.

[36] W. G. Fisher, E. A. Wachter, F. E. Lytle, M. Armas, C. Seaton, Appl. Spectrosc. 1998, 52, 536-545.

Received: August 3, 2012

Published online: November 22, 2012 